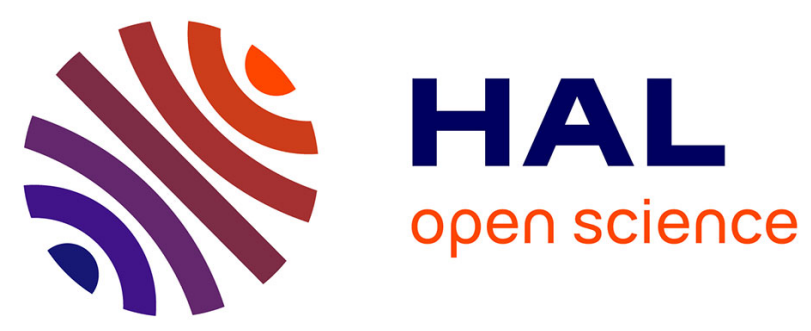

\title{
Nanoparticle Ripening: A Versatile Approach for the Size and Shape Control of Metallic Iron Nanoparticles
}

\author{
Lise-Marie Lacroix, Anca Meffre, Christophe Gatel, Pier-Francesco Fazzini,
} Sébastien Lachaize, Marc Respaud, Bruno Chaudret

\section{- To cite this version:}

Lise-Marie Lacroix, Anca Meffre, Christophe Gatel, Pier-Francesco Fazzini, Sébastien Lachaize, et al.. Nanoparticle Ripening: A Versatile Approach for the Size and Shape Control of Metallic Iron Nanoparticles. ChemPlusChem, 2019, 84 (3), pp.302-306. 10.1002/cplu.201800665 . hal-03156675

\section{HAL Id: hal-03156675 \\ https://hal.science/hal-03156675}

Submitted on 2 Mar 2021

HAL is a multi-disciplinary open access archive for the deposit and dissemination of scientific research documents, whether they are published or not. The documents may come from teaching and research institutions in France or abroad, or from public or private research centers.
L'archive ouverte pluridisciplinaire HAL, est destinée au dépôt et à la diffusion de documents scientifiques de niveau recherche, publiés ou non, émanant des établissements d'enseignement et de recherche français ou étrangers, des laboratoires publics ou privés. 


\title{
Nanoparticle Ripening : A Versatile Approach for the Size and Shape Control of Metallic Iron Nanoparticles.
}

Dr. Lise-Marie Lacroix, ${ }^{1}{ }^{*}$ Dr. Anca Meffre, ${ }^{1}$ Dr. Christophe Gatel, ${ }^{2}$ Dr. Pier-Francesco Fazzini, ${ }^{1}$ Dr. Sébastien Lachaize, ${ }^{1}$ Prof. Marc Respaud, ${ }^{1}$ Dr. Bruno Chaudret ${ }^{1}$

1. Université de Toulouse, INSA, UPS, LPCNO (Laboratoire de Physique et Chimie des Nano-Objets), F-31077 Toulouse, France; CNRS; UMR 5215 ; LPCNO, F-31077 Toulouse, France

2. CEMES-CNRS, 29 rue J. Marvig, BP4347, 31055 Toulouse, France

* corresponding author : email, lmlacroi@insa-toulouse.fr; phone +33561559652, fax $+33561559697$

Supporting Information is available

\begin{abstract}
A novel approach for the synthesis of $\mathrm{Fe}(0)$ nanoparticles (NPs) with tunable sizes and shapes is reported. Ultrasmall $\mathrm{Fe}(0) \mathrm{NPs}$ were reacted under mild conditions in the presence of a mixture of palmitic acid and amine ligands. These NPs acted not only as preformed seeds but also as an internal iron(II) source that was produced by the partial dissolution of the NPs by the acid. This fairly simple approach allows a strict separation between the nucleation and the growth steps. By changing the acid concentration, a fine tuning of the relative ratio between remaining $\mathrm{Fe}(0)$ seeds and iron(II) reservoir was achieved, giving access to both size (from 7 to $20 \mathrm{~nm}$ ) and a shape (spheres, cubes or stars) control. The partial dissolution of the ultrasmall $\mathrm{Fe}(0) \mathrm{NPs}$ into iron(II) source and the successive growth was further studied by using combined TEM and Mössbauer spectroscopy. The successive corrosion, coalescence, and ripening observed could be understood in the framework of an environment-dependent growth model.
\end{abstract}

Key words : Moessbauer spectroscopy, iron, magnetic properties, nanoparticles, seeded growth 


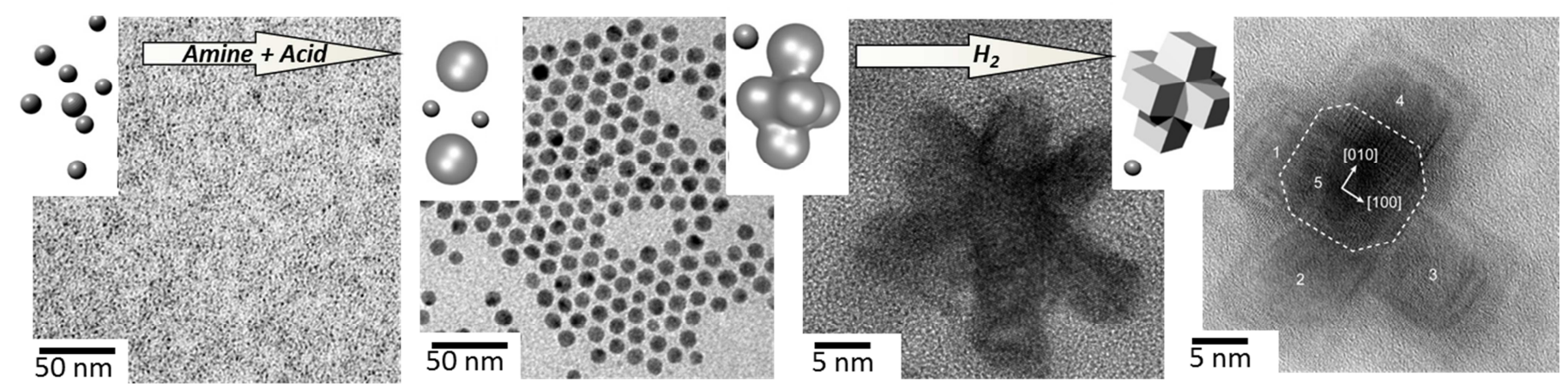

Taking benefice of nanoparticle ripening, we report the use of ultrathin $\mathrm{Fe}(0)$ nanoparticles as a new iron source for the size and shape control of metallic NPs. Playing with the atmosphere conditions, isotropic growth or oriented attachment can be selectively favored. The key role played by the hydrogen in the final faceting is evidenced, leading to highly crystalline Fe nanostars or nanocubes. 


\section{INTRODUCTION}

Magnetic nanoparticles (NPs) are objects of choice for a wide range of applications, ${ }^{[1]}$ such as data storage,${ }^{[2],[3]}$ catalysis, ${ }^{[4]}$ and biomedical ones. ${ }^{[5],[6]}$ Among the different properties sought, the potential overheating of the nanoparticles in presence of an alternate magnetic field received tremendous interest due to its implication on Magnetic Field Hyperthermia (MFH) treatment $^{[7]}$ and thermally-assisted catalysis. ${ }^{[8],[9]}$ To benefit from optimized heating properties, high saturation magnetization $\left(\mathrm{M}_{\mathrm{S}}\right)$ materials are mandatory. ${ }^{[10],[11]}$ Metallic $\mathrm{Fe}$ NPs exhibit magnetization far above their oxide counterparts. However, due to the reactivity of iron towards oxidation, synthesis and stabilization of such fully metallic nanoobjects remains a challenge. ${ }^{[12]}$ The thermodecomposition of $\mathrm{Fe}(\mathrm{CO})_{5}$ in the presence of long-chain ligands has been used in several occasions. ${ }^{[13],[14]}$ However, the magnetic properties of these NPs are usually degraded compared to bulk values due to synthesis by-products such as carbon and oxygen impurities. Recently, alternative precursors such as $\mathrm{Fe}(\text { oleate })_{3}{ }^{[15]}$ $\mathrm{Fe}\left(\mathrm{C}_{5} \mathrm{H}_{5}\right)\left(\mathrm{C}_{6} \mathrm{H}_{7}\right),{ }^{[16]}$ or $\mathrm{Fe}\left\{\mathrm{N}\left[\mathrm{Si}\left(\mathrm{CH}_{3}\right)_{3}\right]_{2}\right\}_{2},{ }^{[17]}$ leads to NPs exhibiting high magnetization and narrow size distribution. Yet, the control of the nanoparticle size and shape, and thus the physical properties of the objects have scarcely been addressed. ${ }^{[18]}$ In contrast to Co and CoNi alloy, for which anisotropic shapes could be reached by tailoring the adopted crystalline structure, ${ }^{[19],[20]}$ such morphological control was not yet achieved for Fe, which exposes a body centered cubic structure. To reach the nanoscale design required for the fine tuning of both size and shape of Fe NPs, a deep understanding of the underlying nucleation and growth mechanisms is needed.

Following an organometallic approach, we were able to produce nanoparticles with a mean diameter ranging between 1.5 and $9 \mathrm{~nm},{ }^{[18]}$ and single crystal nanocubes self-organized into micrometric superlattices by reduction of $\left\{\mathrm{Fe}\left[\mathrm{N}\left(\mathrm{SiMe}_{3}\right)_{2}\right]_{2}\right\}_{2}\left(\mathrm{Me}=\mathrm{CH}_{3}\right)$ in presence of long chain acid and amine under $\mathrm{H}_{2}$ at $150^{\circ} \mathrm{C} .^{[17]}$ Thanks to a detailed kinetic study and the 
characterization of the intermediate complexes formed in-situ, among which Fe carboxylate, we could propose a complex 3-step mechanism to rationalize the synthesis. First, as classically invoked, nucleation proceeded. Then, a growth occurred concomitantly to a coalescence step, in presence of an amine rich environment. Finally a growth-ripening step is observed, induced by the release of carboxylate. Playing with the experimental conditions one can favor any of these three steps. Lowering the reaction temperature or changing the amine/acid allowed favoring the coalescence, yielding stars ${ }^{[18]}$ and porous cubes. ${ }^{[21]}$ Replacing carboxylic acid by ammonium chloride salt changed the iron intermediates formed and thus fastened the reaction kinetic, yielding larger spheres and cubes. ${ }^{[22],[23],[24]}$ To go beyond these results, we now need to gain control on the initial nucleation step. In the literature, the use of preformed seeds, in the so-called seeded-growth process, ${ }^{[25],[26]}$ leads to the strict separation of the nucleation and the growth processes. Pt seeds have been successfully used to promote the heterogeneous growth of Fe NPs by thermodecomposition of $\mathrm{Fe}(\mathrm{CO})_{5} \cdot{ }^{[13],[27]}$ Recently, our group reported the overgrowth of $\mathrm{Fe}$ cubes onto preformed Co nanorods using $\left\{\mathrm{Fe}\left[\mathrm{N}\left(\mathrm{SiMe}_{3}\right)_{2}\right]_{2}\right\}_{2} \cdot{ }^{[28]}$ Here, we propose a different approach where ultrasmall $\mathrm{Fe}(0) \mathrm{NPs}$ of $1.5 \mathrm{~nm}^{[29]}$ were used both as seeds and as Fe source, the idea behind consisting in taking advantage of the ripening step observed in the presence of carboxylic acid. The key role played by the hydrogen was evidenced by a combined transmission electron microscopy (TEM) and Mössbauer spectroscopy study.

\section{RESULTS \& DISCUSSION:}

$1.5 \mathrm{~nm}$ nanoparticles (NPs) were obtained by decomposing $\left\{\mathrm{Fe}\left[\mathrm{N}\left(\mathrm{SiMe}_{3}\right)_{2}\right]_{2}\right\}_{2}$ at $150^{\circ} \mathrm{C}$ under 3 bars of dihydrogen. ${ }^{[29]}$ These ultrasmall particles were further used without 
any purification as reactive $\mathrm{Fe}(0)$ seeds. Ageing these seeds at $150^{\circ} \mathrm{C}$ with a mixture of ligands (palmitic acid, PA and hexadecylamine, HDA, Figure 1) under controlled atmosphere $\left(\mathrm{H}_{2}\right.$ or Ar) yield larger nanoparticles. Contrarily to the classical seeded-growth method used, no external iron source was added, the reactive $\mathrm{Fe}(0)$ seeds initially introduced being partly dissolved to form stable iron(II) species, they acted both as seeds and iron source, as further detailed below.

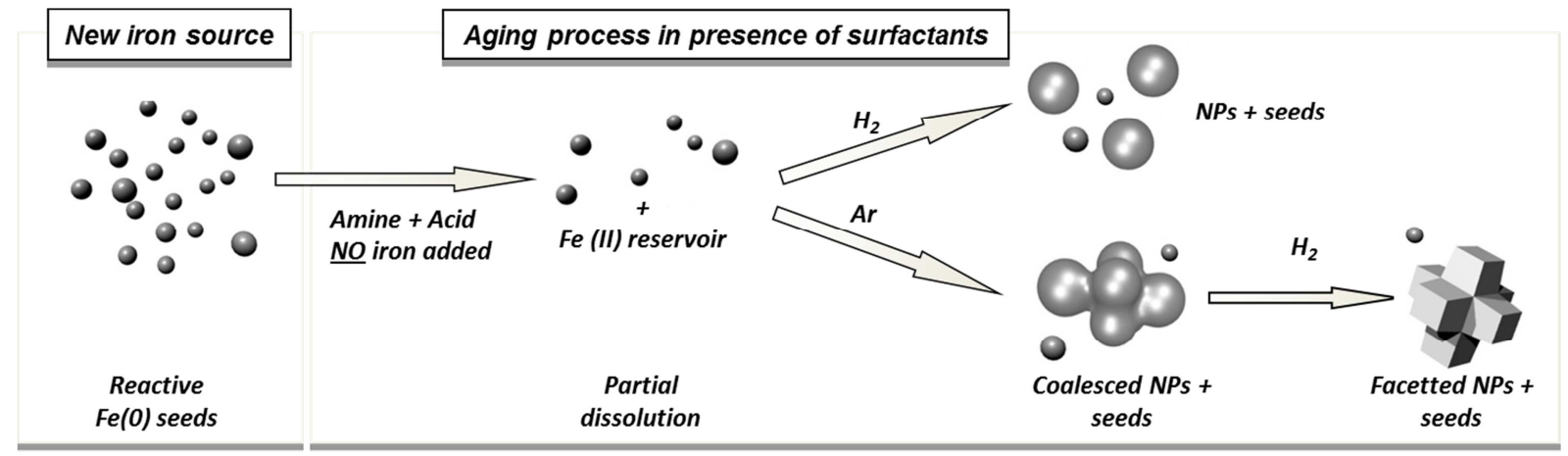

Figure 1. Schematic view of the aging process of reactive $\mathrm{Fe}(0)$ seeds in presence of amine/acid ligand mixtures. Depending on the atmosphere, a growth or a complex coalescence/ripening can be observed.

The effect of the acid concentration on the aging process of $\mathrm{Fe}(0)$ seeds was studied at $150^{\circ} \mathrm{C}$ under $\mathrm{H}_{2}$ atmosphere while keeping the amine concentration constant $([\mathrm{HDA}]=100 \mathrm{mM})$. In presence of $50 \mathrm{mM}$ of palmitic acid, $7.0 \pm 0.1 \mathrm{~nm}$ NPs were observed after 7 days of reaction at $150^{\circ} \mathrm{C}$. Increasing the acid concentration to $75 \mathrm{mM}$ yielded slightly larger NPs exhibiting a mean diameter of $8.0 \pm 0.1 \mathrm{~nm}$ NPs. In presence of an equi-proportion of acid and amine $(100 \mathrm{mM})$, the reaction was fastened as revealed by the important precipitation of $10.2 \pm 0.1$ nm NPs onto the magnetic stirrer after only 48 h of ageing (Figure 2 and S1).

The final state of the ageing process, corresponding to the full reaction of the preformed $\mathrm{Fe}(0)$ seeds was never achieved. Indeed, unreacted seeds remained even after extended reaction 
time (up to 28 days) as characterized by TEM and zero-field cooling/field cooling magnetic measurements (Figure S2).

Large $\mathrm{Fe}(0)$ NPs could be easily retrieved from the reaction media using conventional centrifugation process. For instance, $10.2 \mathrm{~nm}$ NPs could be sorted and further characterized (Figure S3). The particles are highly crystalline and exhibit the expected bcc-Fe structure as revealed by X-Ray Diffraction (Figure 2e). Magnetic measurements performed at low temperature revealed a saturation magnetization of $215 \mathrm{Am}^{2} \mathrm{~kg}^{-1}$, similar to the bulk value (Figure 2f). Mössbauer spectroscopy confirmed a pure $\mathrm{Fe}(0)$ composition, as revealed by the single sextet observed (Figure S3b). 

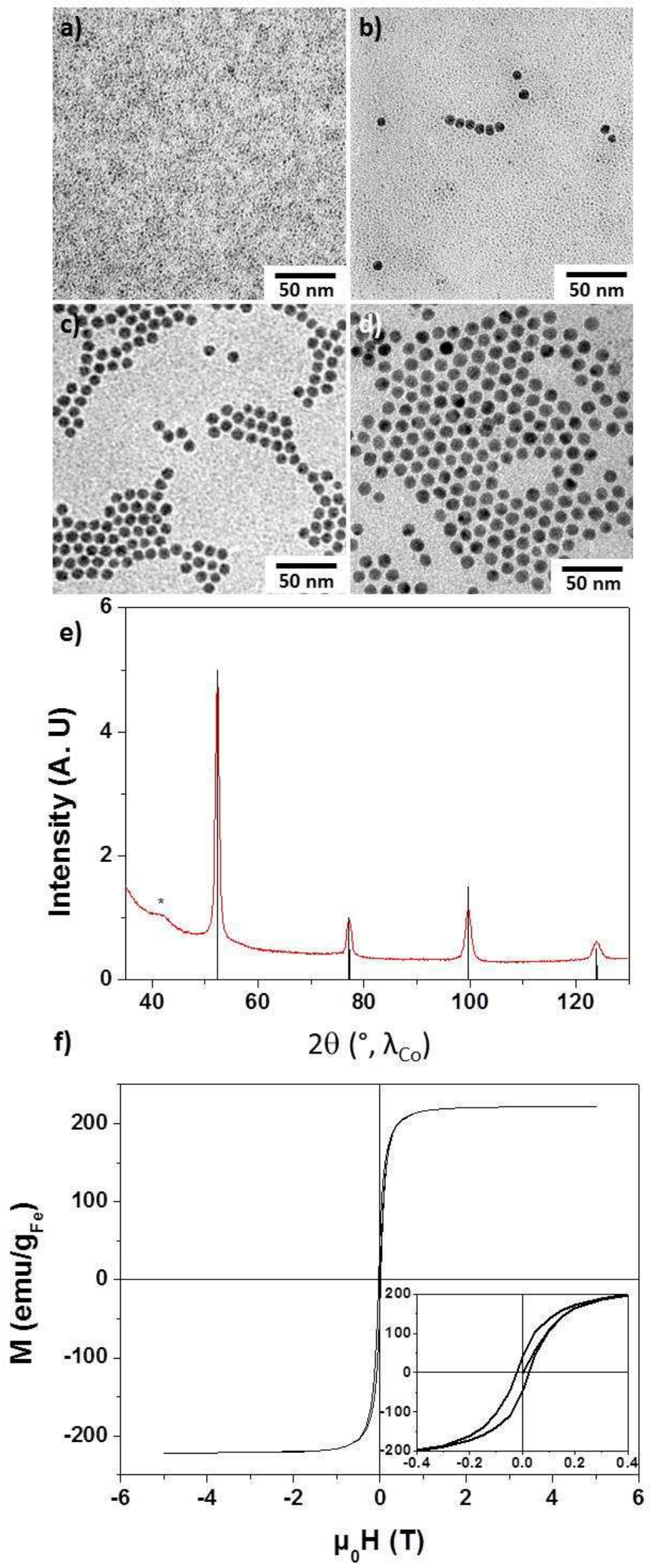
Figure 2. Transmission electron microscopy (TEM) images of Fe NPs obtained from a) $\mathrm{Fe}(0)$ seeds after an aging process of $(b-c) 7$ days and d) 2 days in presence of 100mM of HDA and b) 50, c) 75 and d) $100 \mathrm{mM}$ of PA. Scale bar corresponds to $50 \mathrm{~nm}$. e) XRD pattern and f) Hysteresis cycle measured at $2 \mathrm{~K}$ after a $5 \mathrm{~T}$ field-cooling of the $10 \mathrm{~nm}$ spheres observed in d) after purification process. As inset : zoom of the +/- $400 \mathrm{mT}$ region, evidencing the absence of any exchange bias. The black lines in e) correspond to the bcc-Fe reference pattern (PDF-00-006-0696).

Starting from metallic $\mathrm{Fe}(0)$ seeds as new iron source for the synthesis of large NPs, the question of the role of $\mathrm{H}_{2}$, classically used as a strong reducing agent, naturally rose up. Therefore a comparative study in absence of $\mathrm{H}_{2}$ was performed. $\mathrm{Fe}(0)$ seeds were aged during $48 \mathrm{~h}$ at $150^{\circ} \mathrm{C}$ under $\mathrm{Ar}$ in presence of an equi-concentration of PA and HDA (100mM). While $10.2 \mathrm{~nm}$ NPs were previously obtained under similar condition in $\mathrm{H}_{2}$ atmosphere, large starlike shaped NPs were synthesized (Figure 3a). High resolution transmission electron microscope (HREM) revealed that these Fe NPs were single-crystalline but they do not exhibit any preferential exposed facets (Figure 3b).

Similar ill-defined nanoparticles were previously observed as intermediate states prior to the stabilization of $\mathrm{Fe}$ nanocubes during the direct reduction of $\left\{\mathrm{Fe}\left[\mathrm{N}\left(\mathrm{SiMe}_{3}\right)_{2}\right]_{2}\right\}_{2} .{ }^{\left[{ }^{[28}\right] \mathrm{We}}$ invoked at that time an oriented-coalescence phenomenon in presence of an amine rich environment to explain the growth of such objects. Since we previously reported a successive ripening process which promoted the stabilization of $\{100\}$ facets on Fe nanocubes, we tried to further extend the reaction time on our star-like shaped NPs up to $96 \mathrm{~h}$ at $150^{\circ} \mathrm{C}$ under $\mathrm{Ar}$. However, the stars were fairly stable and no sign of shape evolution was detected (Figure S4).

On the contrary, allowing the star-like shaped NPs to react under $\mathrm{H}_{2}$ at $150^{\circ} \mathrm{C}$ yielded facetted NPs (Figure 3c-d). HREM image and the corresponding Fourier transform (FT) confirmed that the facetted stars remained single-crystalline and clearly exhibit mostly $\{100\}$ facets (Figure 3d and S5). The additional peaks appearing in the FT were due to the oxide shell 
formed after air exposure of the sample during the deposition of nanoparticles on the carbon foil and the insertion into the electron microscope.

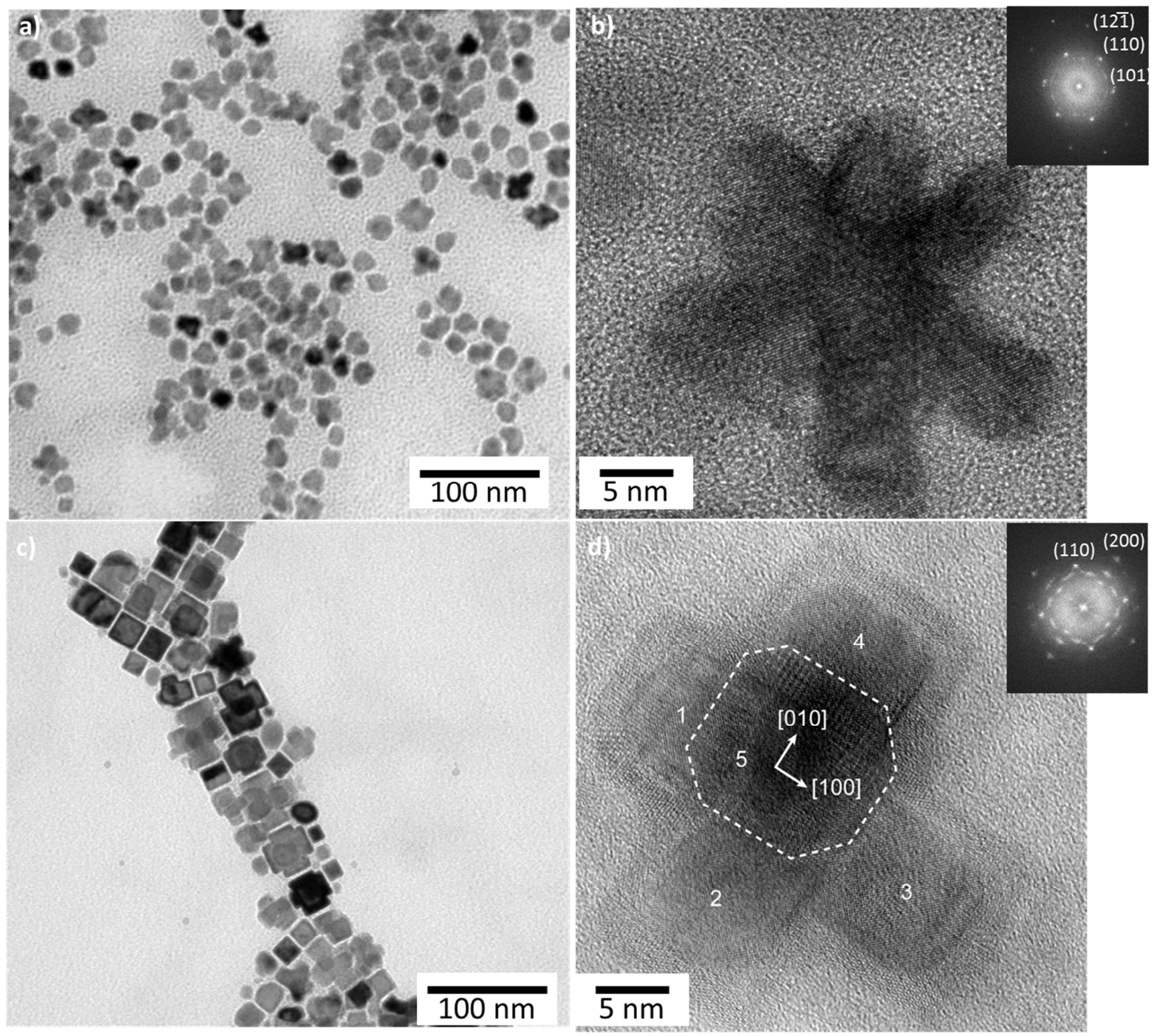

Figure 3. $a-c)$ TEM and b-d) HREM images of Fe NPs obtained in presence of $100 \mathrm{mM}$ of PA and 100mM of HDA after $a-b)$ a 48h aging process under Ar and c-d) after an additional 48h aging under $\mathrm{H}_{2}$. As inset : corresponding FT pattern confirming the bcc structure observed along [111] and [001] zone axis.

Playing with the ligand concentration, the size of the coalesced particles obtained after $48 \mathrm{~h}$ of aging under Ar could be tuned between ca. $10 \mathrm{~nm}$ (50mM PA/ $100 \mathrm{mM}$ HDA) and $25 \mathrm{~nm}$ (100mM PA/ 200mM HDA) (Figure S6). Once more, an additional ageing step under $\mathrm{H}_{2}$ 
allowed for the faceting of these particles, leading to nanocubes and nanostars exhibiting $\{100\}$ facets (Figure S7).

To go beyond morphological observations, a Mössbauer spectroscopy study was performed. Figure 4 shows the evolution of Mössbauer spectroscopy patterns of $\mathrm{Fe}(0)$ seeds in presence of $100 \mathrm{mM}$ of PA and $100 \mathrm{mM}$ of HDA as a function of the reaction time under either $\mathrm{H}_{2}$ or Ar atmosphere. The spectra of the raw samples have been collected at low temperature $5 \mathrm{~K}$, to limit relaxation phenomena from superparamagnetic small Fe clusters. The analysis of the spectra was done on the basis of our previous Mössbauer investigations, for the seeds only ${ }^{[35]}$, and for the synthesis of NPs in presence of PA/HDA from the decomposition of $\left\{\mathrm{Fe}\left[\mathrm{N}\left(\mathrm{SiMe}_{3}\right)_{2}\right]_{2}\right\}_{2}{ }^{[18]}$ Indeed, similar nano-objects and complexes are likely, as similar $\mathrm{Fe}$ precursor and ligands are used. All the spectra were then fitted with 4 contributions : Fe seeds ${ }^{[35]}$, ferromagnetic $\mathrm{Fe}$, an extended phase named as $[\mathrm{Fe}]_{\mathrm{u} \_1}$ in [18], and molecular $\mathrm{Fe}(\mathrm{II})$ contributions. $[\mathrm{Fe}]_{\mathrm{u}_{-} 1}$ is not identified, but its high isomeric shift and the large hyperfine field are indicative of the presence of magnetically coupled Fe ions, in an acid environment. The different contributions are detailed in the supplementary information (Table S1, and Figure S8). At room temperature, the $\mathrm{Fe}(0)$ seeds quickly evolved, leading to the formation of a molecular complex iron(II) comparable to carboxylate species, as evidenced by the doublet observed at $\mathrm{t}=0 .{ }^{[18]}$ The seed corrosion was however not total, as revealed by the persistence of the seed signature. With time the molecular Fe(II) complex evolved to form the stable $[\mathrm{Fe}]_{\mathrm{u} \_1}$ species. In the following section the $\mathrm{Fe}(\mathrm{II})$ reservoir will refer to both $\mathrm{Fe}(\mathrm{II})$ molecular and $[\mathrm{Fe}]_{\mathrm{u}_{-} 1}$ species.

Under $\mathrm{H}_{2}$, metallic $\mathrm{Fe}(0)$ species grew significantly but unreacted $\mathrm{Fe}(0)$ seeds along with $\mathrm{Fe}(\mathrm{II})$ reservoir remained after $48 \mathrm{~h}$ (Table 1). The time evolution of the reaction was followed by a combined TEM study. Spheres grew homogeneously as revealed by TEM, their size increasing continuously from $2.8 \pm 0.2 \mathrm{~nm}$ after $30 \mathrm{~min}$ to $7.1 \pm 0.1 \mathrm{~nm}$ after $6 \mathrm{~h}, 8.2 \pm 0.1 \mathrm{~nm}$ 
after $12 \mathrm{~h}$ and $9.9 \pm 0.1 \mathrm{~nm}$ after $24 \mathrm{~h}$ (Figure S9). The final size of $10.2 \pm 0.1 \mathrm{~nm}$ was finally reached after $48 \mathrm{~h}$ of reaction. Extended further the reaction time did not promote a further decomposition of the $\mathrm{Fe}(\mathrm{II})$ reservoir but rather lead to a size broadening. The complete reduction of the $\mathrm{Fe}(\mathrm{II})$ reservoir was also not achieved by direct decomposition of $\left\{\mathrm{Fe}\left[\mathrm{N}\left(\mathrm{SiMe}_{3}\right)_{2}\right]_{2}\right\}_{2},{ }^{[18]}$ a competition being observed between the $\mathrm{Fe}(\mathrm{II})$ species reduction, which induced the liberation of acid species and the further corrosion of $\mathrm{Fe}(0)$ seeds.

Under Ar atmosphere, the corrosion of the $\mathrm{Fe}(0)$ seeds to give molecular complexes was also evidenced. After $3 \mathrm{~h}, 60 \%$ of unreacted seeds still remained, while a small amount of $\mathrm{Fe}(0)$ NPs, not detected by Mössbauer were formed as revealed by TEM (Figure S10). Extending the reaction time up to $48 \mathrm{~h}$ allows the stabilization of a larger proportion of $\mathrm{Fe}(\mathrm{II})$ reservoir, resulting from the seeds corrosion. The contribution of the star-like shaped Fe(0) NPs was limited to $16 \%$, revealing that the reaction was far from being complete. 


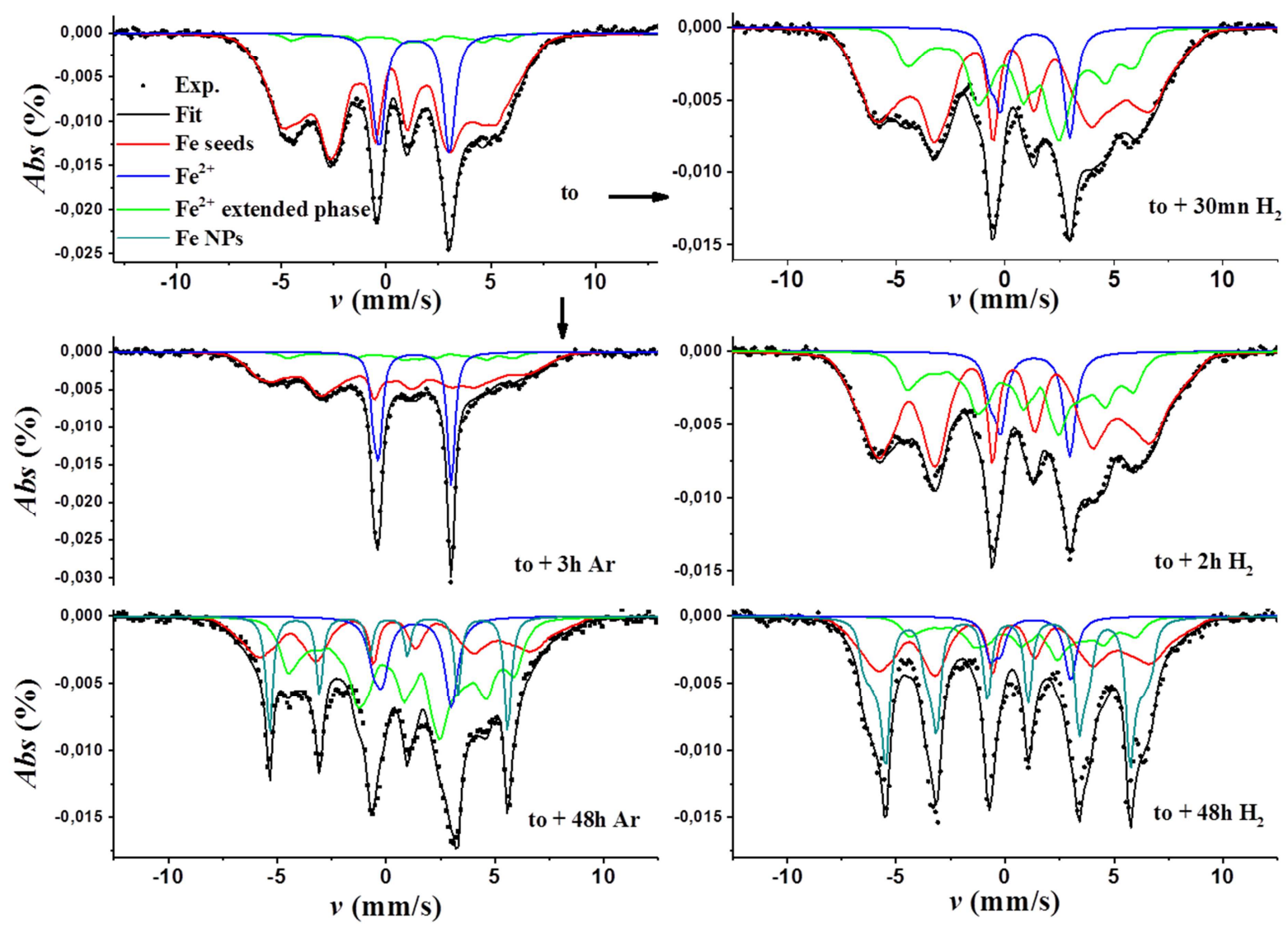

Figure 4. Mössbauer spectra measured at $5 \mathrm{~K}$ of Fe seeds ripened in presence of $100 \mathrm{mM}$ of $P A$ and $100 \mathrm{mM}$ of $\mathrm{HDA}$ at $150^{\circ} \mathrm{C}$ after different reaction time under Ar or $\mathrm{H}_{2}$.

\begin{tabular}{|c|c|c|c|c|c|}
\hline Atmosphere & Time & Iron(II) & $\begin{array}{c}{[\mathrm{Fe}]_{\mathrm{u} \_} 1} \\
\text { extended phase }\end{array}$ & Fe seeds & $\mathrm{Fe}(0) \mathrm{NPs}$ \\
\hline \multirow{2}{*}{ Ar or $\mathrm{H}_{2}$} & $\mathrm{t}_{0}$ & $17 \%$ & $5 \%$ & $78 \%$ & - \\
\hline \multirow{2}{*}{$\mathrm{Ar}$} & $3 \mathrm{~h}$ & $31 \%$ & $9 \%$ & $60 \%$ & - \\
\cline { 2 - 6 } & $48 \mathrm{~h}$ & $12 \%$ & $48 \%$ & $24 \%$ & $16 \%$ \\
\hline \multirow{2}{*}{$\mathrm{H}_{2}$} & $30 \mathrm{mn}$ & $12 \%$ & $25 \%$ & $63 \%$ & - \\
\cline { 2 - 6 } & $2 \mathrm{~h}$ & $12 \%$ & $28 \%$ & $60 \%$ & - \\
\cline { 2 - 6 } & $48 \mathrm{~h}$ & $8 \%$ & $16 \%$ & $34 \%$ & $42 \%$ \\
\hline
\end{tabular}

Tablel. Evolution of the different contributions deduced from Mössbauer spectra as a function of the reaction duration under Ar or $\mathrm{H}_{2}$. 
Ultrasmall $\mathrm{Fe}(0) \mathrm{NPs}$ were observed to be reactive at $150^{\circ} \mathrm{C}$ under $\mathrm{H}_{2}$ in presence of a mixture of acid/amine ligands. An important proportion was corroded to form a fairly stable iron(II) reservoir which allows for the growth of the remaining unreacted seeds. Ultrasmall $\mathrm{Fe}(0)$ seeds acted thus not only as seeds but also as an internal iron source in this new approach. As expected the final size of the objects could be finely tuned by playing with the acid/amine ratio which governs the relative balance between the remaining seeds and the iron(II) reservoir. The higher the acid content, the larger the final NPs due to an extended iron(II) reservoir.

When the aging reaction was performed in presence of Ar atmosphere, the kinetic of both, the seed corrosion and the reduction of the iron(II) reservoir drastically slow down. Few star-like shaped nanoparticles were obtained, probably due to a coalescence process in an amine-rich like environment, as previously invoked for the direct synthesis of Fe NPs. ${ }^{[18]}$ Thanks to a successive aging step in the presence of $\mathrm{H}_{2}$, NPs evolved to exhibit mainly (100) facets probably thanks to a growth-reparation mechanism when the acid molecules are slowly retrieved from the iron(II) reservoir, as previously proposed for the direct synthesis of $\mathrm{Fe}$ NPs. ${ }^{[18]}$

\section{CONCLUSION :}

We report here a novel approach for the synthesis of metallic Fe nanoparticles, using ultrasmall NPs as seeds and iron source. In presence of acid/amine environment a complex ripening/coalescence occurs allowing a fine tuning of the final size and shape of the $\operatorname{Fe}(0)$ objects obtained. For the first time, star-like shaped Fe NPs exhibiting controlled facets could be reproducibly produced, opening the way for the stabilization of complex 3D magnetic structures. We believe that such simple approach could become a generic method for metallic 
NPs synthesis exhibiting complex shapes, indeed, preliminary studies have shown that it can be successfully transposed to $\operatorname{Co}(0)$ synthesis.

\section{Experimental section :}

\section{Chemicals and Materials.}

Due to the air sensitivity of the precursors and nanoparticles obtained, all synthesis were prepared under argon atmosphere by using Fischer-Porter bottles technique, glove box and argon/vacuum lines. Mesitylene (99\% Fluka) and toluene (99\%, VWR Prolabo), were distilled, degassed and transferred in the glove box prior to use. Hexadecylamine (HDA, 99\%) and palmitic acid (PA, 99\%) were purchased from Sigma Aldrich and used without any additional purification. The bis(amido)iron dimer $\left\{\mathrm{Fe}\left[\mathrm{N}\left(\mathrm{SiMe}_{3}\right)_{2}\right]_{2}\right\}_{2}\left(\mathrm{Me}=\mathrm{CH}_{3}\right)$ was purchased from Nanomeps.

\section{Synthesis of iron (0) nanoparticles}

Step 1: Synthesis of preformed Fe(0) seeds.

Preformed $\mathrm{Fe}(0)$ seeds were prepared according to a previous procedure. ${ }^{[2]}$ Briefly, in an $\mathrm{Ar}$ glove box, a green solution of $\left\{\mathrm{Fe}\left[\mathrm{N}\left(\mathrm{SiMe}_{3}\right)_{2}\right]_{2}\right\}_{2}\left(\mathrm{Me}=\mathrm{CH}_{3}\right)(0.5 \mathrm{mmol}, 376 \mathrm{mg}$, corresponding to a Fe concentration of $50 \mathrm{mM}$ ) in $20 \mathrm{ml}$ of mesitylene was transferred into a Fischer Porter bottle. The bottle was pressurized with 3 bars of dihydrogen for 10 minutes, and then transferred to a preheated oil bath at $150^{\circ} \mathrm{C}$. The solution evolved quickly: after few minutes its color turned to black. The reaction was let to react $24 \mathrm{~h}$ at $150^{\circ} \mathrm{C}$ under vigorous magnetic stirring, leading to a $20 \mathrm{~mL}$ black solution. After cooling down to room temperature, the reducing atmosphere was removed and the obtained solution was stored in the glove box. 
Spherical nanoparticles of 1.5-2.0 $\mathrm{nm}$ in diameter homogeneous in size were quantitatively obtained.

Step 2: Ripening in presence of a mixture of ligands.

$5 \mathrm{~mL}$ of the obtained $\mathrm{Fe}(0)$ seed solution was used without any further purification and transferred into a Fisher Porter bottle. Palmitic acid (PA) and hexadecylamine (HDA) were added and carefully dissolved thanks to a strong magnetic stirring. The solution was then placed in an oil bath and allowed to react under 3 bars at $150^{\circ} \mathrm{C}$ for 2 to 7 days.

* Synthesis of $10 \mathrm{~nm}$ spherical nanoparticles. Typically $128 \mathrm{mg}$ of PA (0.5 mmol, 100mM) and $121 \mathrm{mg}$ of hexadecylamine $(0.5 \mathrm{mmol} 100 \mathrm{mM})$ were added to the $5 \mathrm{~mL}$ seed solution. 10 nm NPs were obtained after $48 \mathrm{~h}$ of reaction under $\mathrm{H}_{2}$ at $150^{\circ} \mathrm{C}$. Smaller NPs of 7 and $8 \mathrm{~nm}$ could be obtained by decreasing the acid content down to $64 \mathrm{mg}(0.25 \mathrm{mmol}, 50 \mathrm{mM})$ and 96 $\mathrm{mg}(0.375 \mathrm{mmol}, 75 \mathrm{mM})$ respectively, keeping an amine content of $0.5 \mathrm{mmol}(100 \mathrm{mM})$. The reaction time was extended to 7 days under $\mathrm{H}_{2}$ to counterbalance the decrease of reactivity observed.

* Synthesis of star-like shaped particles. Typically $128 \mathrm{mg}$ of PA (0.5 mmol, 100mM) and $121 \mathrm{mg}$ of hexadecylamine $(0.5 \mathrm{mmol}, 100 \mathrm{mM})$ were added to the $5 \mathrm{~mL}$ seed solution. After $48 \mathrm{~h}$ of reaction at $150^{\circ} \mathrm{C}$ under Ar, large coalesced NPs were obtained. The obtained solution was pressurized under 3 bars of $\mathrm{H}_{2}$ and allowed to react further at $150^{\circ} \mathrm{C}$ for an additional 48h. Star-like shapes particles exhibiting controlled facets were finally obtained.

\section{Characterization of the NPs.}

Microscopy samples were prepared by deposition of a diluted colloidal solution drop on a carbon coated copper grid and observed on a JEOL-1011 for Bright Field Transmission 
Electronic Microscopy (TEM) and aberration corrected Tecnai F-20 microscope for High Resolution-TEM (HRTEM) working with $100 \mathrm{kV}$ and $200 \mathrm{kV}$ respectively. In the majority of cases, size histograms were obtained by manual counting process over at least 100 particles, using ImageJ software. ${ }^{[30]}$ Size distributions have been fitted by Gaussian law; the results are expressed by the calculated mean size and standard deviation $\sigma$. Magnetic studies were carried out on powder samples by SQuID (MPMS Quantum Design 5.5) and the iron state and environment were analysed by Mössbauer spectroscopy (WISSEL, ${ }^{57}$ Co source). Samples were prepared into the glove box and extreme care was taken to avoid oxidation during transfer to the apparatus. Microanalysis measurements were performed by ICP (Inductively Coupled Plasma).

\section{Acknowledgment :}

This work was supported by the French national project EMMA (ANR12 BS10 013 01) and the French microscopy network METSA.

[1] A.-H. Lu, E. L. Salabas, F. Schüth, Angew. Chem. Int. Ed. 2007, 46, 1222-1244.

[2] S. Sun, Adv. Mater. 2006, 18, 393-403.

[3] N. Liakakos, T. Blon, C. Achkar, V. Vilar, B. Cormary, R. P. Tan, O. Benamara, G. Chaboussant, F. Ott, B. Warot-Fonrose, E. Snoeck, B. Chaudret, K. Soulantica, M. Respaud, Nano Lett. 2014, 14, 3481-3486.

[4] Y. Zhu, L. P. Stubbs, F. Ho, R. Liu, C. P. Ship, J. A. Maguire, N. S. Hosmane, ChemCatChem 2010, 2, 365-374.

[5] L.-S. Bouchard, M. S. Anwar, G. L. Liu, B. Hann, Z. H. Xie, J. W. Gray, X. Wang, A. Pines, F. F. Chen, Proc. Natl. Acad. Sci. 2009, 106, 4085-4089.

[6] J. B. Haun, T.-J. Yoon, H. Lee, R. Weissleder, Wiley Interdiscip. Rev. Nanomed. Nanobiotechnol. 2010, 2, 291-304.

[7] L.-M. Lacroix, D. Ho, S. Sun, Curr. Top. Med. Chem. 2010, 10, 1184-1197.

[8] A. Bordet, L.-M. Lacroix, P.-F. Fazzini, J. Carrey, K. Soulantica, B. Chaudret, Angew. Chem. Int. Ed. 2016, 55, 15894-15898.

[9] A. Meffre, B. Mehdaoui, V. Connord, J. Carrey, P. F. Fazzini, S. Lachaize, M. Respaud, B. Chaudret, Nano Lett. 2015, 15, 3241-3248. 
[10] B. Mehdaoui, A. Meffre, J. Carrey, S. Lachaize, L.-M. Lacroix, M. Gougeon, B. Chaudret, M. Respaud, Adv. Funct. Mater. 2011, 21, 4573-4581.

[11] J. Carrey, B. Mehdaoui, M. Respaud, J. Appl. Phys. 2011, 109, 83921.

[12] D. Huber, Small 2005, 1, 482-501.

[13] D. Farrell, S. A. Majetich, J. P. Wilcoxon, J. Phys. Chem. B 2003, 107, 11022-11030.

[14] S. Peng, C. Wang, J. Xie, S. Sun, J. Am. Chem. Soc. 2006, 128, 10676-10677.

[15] A. Shavel, B. Rodríguez-González, M. Spasova, M. Farle, L. M. Liz-Marzán, Adv. Funct. Mater. 2007, 17, 3870-3876.

[16] S. Cheong, P. Ferguson, K. W. Feindel, I. F. Hermans, P. T. Callaghan, C. Meyer, A. Slocombe, C.-H. Su, F.-Y. Cheng, C.-S. Yeh, B. Ingham, M. F. Toney, R. D. Tilley, Angew. Chem. Int. Ed. 2011, 50, 4206-4209.

[17] F. Dumestre, Science 2004, 303, 821-823.

[18] L.-M. Lacroix, S. Lachaize, A. Falqui, M. Respaud, B. Chaudret, J. Am. Chem. Soc. 2009, 131, 549-557.

[19] A. P. LaGrow, S. Cheong, J. Watt, B. Ingham, M. F. Toney, D. A. Jefferson, R. D. Tilley, Adv. Mater. 2013, 25, 1552-1556.

[20] Y. Soumare, C. Garcia, T. Maurer, G. Chaboussant, F. Ott, F. Fiévet, J.-Y. Piquemal, G. Viau, Adv. Funct. Mater. 2009, 19, 1971-1977.

[21] L.-M. Lacroix, S. Lachaize, F. Hue, C. Gatel, T. Blon, R. P. Tan, J. Carrey, B. WarotFonrose, B. Chaudret, Nano Lett. 2012, 12, 3245-3250.

[22] C. Gatel, F. J. Bonilla, A. Meffre, E. Snoeck, B. Warot-Fonrose, B. Chaudret, L.-M. Lacroix, T. Blon, Nano Lett. 2015, 15, 6952-6957.

[23] A. Meffre, S. Lachaize, C. Gatel, M. Respaud, B. Chaudret, J. Mater. Chem. 2011, 21, 13464.

[24] E. Snoeck, C. Gatel, L. M. Lacroix, T. Blon, S. Lachaize, J. Carrey, M. Respaud, B. Chaudret, Nano Lett. 2008, 8, 4293-4298.

[25] J. Park, E. Lee, N.-M. Hwang, M. Kang, S. C. Kim, Y. Hwang, J.-G. Park, H.-J. Noh, J.Y. Kim, J.-H. Park, T. Hyeon, Angew. Chem. Int. Ed. 2005, 44, 2872-2877.

[26] S. Sun, H. Zeng, J. Am. Chem. Soc. 2002, 124, 8204-8205.

[27] D. Farrell, Y. Cheng, R. W. McCallum, M. Sachan, S. A. Majetich, J. Phys. Chem. B 2005, 109, 13409-13419.

[28] N. Liakakos, C. Gatel, T. Blon, T. Altantzis, S. Lentijo-Mozo, C. Garcia-Marcelot, L.M. Lacroix, M. Respaud, S. Bals, G. Van Tendeloo, K. Soulantica, Nano Lett. 2014, 14, 2747-2754.

[29] L.-M. Lacroix, S. Lachaize, A. Falqui, T. Blon, J. Carrey, M. Respaud, F. Dumestre, C. Amiens, O. Margeat, P. Lecante, E. Snoeck, B. Chaudret, J. Appl. Phys. 2008, 103, $07 \mathrm{D} 521$.

[30] C. A. Schneider, W. S. Rasband, K. W. Eliceiri, Nature methods 2012, 9, 671-675 